\title{
Effect of different cardioprotective methods on extracorporeal circulation in fetal sheep: a randomized controlled trial
}

\author{
Yi-bo Yan', Shuo Shi², Qian-biao Wu², Jin-sheng Cai ${ }^{1}$ and Bin-feng Lei ${ }^{i^{*}}$
}

\begin{abstract}
Background: Congenital heart disease is a leading cause of death in newborns and infants. The feasibility of fetal cardiac surgery is linked to extracorporeal circulation (ECC); therefore, cardioplegic solutions need to be effective and long-lasting.
\end{abstract}

Methods: Eighteen pregnant sheep were divided into an ECC-only group, St. Thomas' Hospital cardioplegic solution (STH1) group (STH group), and HTK preservation solution (Custodio ${ }^{\circledR}$ ) group (HTK group). Markers of myocardial injury including troponin I (CTnl), troponin T (CTnT) and creatine kinase myocardial band (CKMB) were measured at specific time points (T1: pre-ECC, T2: 30 min of ECC, T3: 60 min of ECC, T4: 60 min post-ECC, T5: 120 min post-ECC). Myocardial tissue was removed from the fetal sheep at T5, and apoptosis was detected by TUNEL staining.

Results: Changes in the serum cTnl, CTnT and CKMB concentrations were not significantly different among the three groups before and during the ECC(T1,T2,T3). At 60 min after ECC shutdown(T4), $C T n l$ and cTnT concentrations were significantly higher in the STH group than before the start of ECC. The concentration of cTnl was higher in the STH group than in the HTK and ECC-only groups. The concentration of CTnT was higher in the STH group than in the ECConly group. At 120 min after ECC shutdown(T5), cTnl and CTnT concentrations were significantly higher in the ECC and HTK groups than before the start of ECC, and CKMB concentration was significantly higher in STH and HTK groups. The concentrations of cTnT, cTnl and CKMB was higher in the STH group than in the HTK and ECC-only groups. The number of TUNEL-positive cells in the HTK and STH groups was higher than in the ECC-only group. The number of TUNEL-positive cells in the STH group was higher than in the HTK group. There was no statistically significant difference among the groups in the heart rate and mean arterial pressure after ECC.

Conclusion: The HTK preservation solution was significantly better than STH1 in reducing the release of cardiomyocyte injury markers and the number of apoptotic cells in fetal sheep ECC. Fetal sheep receiving ECC-only had an advantage in all indicators, which suggests ECC-only fetal heart surgery is feasible.

Keywords: Apoptosis, Congenital heart disease, Creatine kinase-muscle band, Extracorporeal circulation, Fetal sheep, HTK preservation solution (Custodiol ${ }^{\circledR}$ ), St Thomas' Hospital cardioplegic solution, Troponin

\footnotetext{
* Correspondence: qq470752889@sina.com

'Department of Cardiac Surgery, The First Affiliated Hospital of Guangxi

Medical University, Nanning, Guangxi Zhuang Autonomous Region, People's Republic of China

Full list of author information is available at the end of the article
}

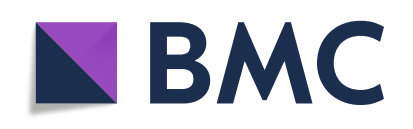

(- The Author(s). 2021 Open Access This article is licensed under a Creative Commons Attribution 4.0 International License, which permits use, sharing, adaptation, distribution and reproduction in any medium or format, as long as you give appropriate credit to the original author(s) and the source, provide a link to the Creative Commons licence, and indicate if changes were made. The images or other third party material in this article are included in the article's Creative Commons licence, unless indicated otherwise in a credit line to the material. If material is not included in the article's Creative Commons licence and your intended use is not permitted by statutory regulation or exceeds the permitted use, you will need to obtain permission directly from the copyright holder. To view a copy of this licence, visit http://creativecommons.org/licenses/by/4.0/. The Creative Commons Public Domain Dedication waiver (http://creativecommons.org/publicdomain/zero/1.0/) applies to the data made available in this article, unless otherwise stated in a credit line to the data. 


\section{Background}

Congenital heart disease is one of the leading causes of death in newborns and infants and accounts for about $1 \%$ of all congenital malformations [1]. Although there have been impressive advances in pediatric cardiac surgery in the last 20 years, some complex cardiac malformations (left ventricular dysplasia syndrome, pulmonary atresia, etc.) still result in high intrauterine death rates, postnatal mortality, and complications [2-4].

The early fetal heart pattern is formed by the eighth week in utero, and further development of the heart is influenced by the pattern of fetal blood flow $[5,6]$. Theoretically, if congenital heart disease can be operated on during the fetal period, the transformation of an abnormality into a complex one can be prevented, complex postnatal cardiac surgery can be avoided, the heart can be given a chance to develop further in utero, and secondary morphologic damage can be avoided [7-9].

The introduction of minimally invasive and robotic techniques in cardiac surgery, the development of fetal anesthesia concepts, advances in ECC technology and improvement in ECC equipment have made fetal cardiac surgery possible. Nevertheless, concerns regarding myocardial protection have been a major hindrance, and the perioperative myocardial injury and postoperative cardiac dysfunction are yet to be addressed [10]. Because of the fetus's unique characteristics, the need for the protection of immature fetal myocardium is much higher than that in the adults. There are significant differences between the immature and mature myocardium in terms of function, ultrastructure, energy metabolism, and tolerance of ischemia and hypoxia. In order to meet the high level of fetal surgical refinement required, cardioplegic solutions need to be effective and prolonged. At present, the protection of immature myocardium is still being explored [11]. Research on the theory of fetal ECC began in 1984, with attempts at ECC in fetal sheep first reported by Slate et al. at the University of California [12]. Based on many experiments on fetal sheep and a thorough understanding of fetal sheep physiology, the technology for ECC in fetal sheeps is largely mature [13].

In this study, we used a small centrifugal pump to establish an extracorporeal circulation model in fetal sheep. We used three ECC methods. The first one is to keep the heart from arresting, which means the hearts are not arrested but just maintained on ECC. The second one is the use of St Thomas' Hospital cardioplegic solution (STH1). The third one is the use of HTK preservation solution $\left(\mathrm{Custodiol}^{\odot}\right)$. We monitored fetal cardiac function and compared the effects of the three methods on fetal sheep, including cardiomyocyte apoptosis and levels of markers of myocardial injury during and after the surgery, given the clinical applicability of this approach.

\section{Materials and methods}

\section{Study design (Fig. 1)}

Eighteen pregnant sheeps (100-120 days gestation, 150 days at term) weighing $25.72 \pm 4.29 \mathrm{~kg}(17.5-32 \mathrm{~kg})$, with 18 fetuses, were used for the study. We divided the fetal sheep into three groups of six: the ECC-only group, the STH group, and the HTK. In the ECC-only group, we established ECC for the fetal sheep for $60 \mathrm{~min}$, then arrested it and observed the sheep for $120 \mathrm{~min}$. In the STH and HTK groups, the ascending aorta of the fetal sheep was occluded, and the heart was perfused with St Thomas' Hospital cardioplegic solution (STH1) and HTK preservation solution $\left(\mathrm{Custodiol}^{\circ}\right)$ to arrest the fetal heart for $30 \mathrm{~min}$. The fetal aorta was then reopened to allow both, body and extracorporeal circulation, and after the heart had successfully resumed beating for 30 min, the ECC was stopped, and the sheep were observed for $120 \mathrm{~min}$.

\section{Preoperative preparation and anesthesia}

Pregnant sheeps were fasted for $24 \mathrm{~h}$. Preoperatively, we prepared the skin of the abdomen, back, and neck of the pregnant sheep and administered a preoperative intramuscular injection of atropine $0.5-1.0 \mathrm{mg} / \mathrm{kg}$ and ketamine $10-20 \mathrm{mg} / \mathrm{kg}$ into the femoral area. After the sheep's conjunctival reflex disappeared, the sheep was lifted onto the operating table, and electrodes were attached to its back. The trachea was intubated, and the sheep were ventilated mechanically with a tidal volume of $10-15 \mathrm{~mL} / \mathrm{kg}$ and an inhalation oxygen concentration of $40-50 \%$, at a frequency of 15-20 times/minute. A cardiac monitor was attached to the forelimb of the pregnant sheep. The femoral artery was punctured and intubated, and an arterial tester was connected to monitor arterial blood pressure. The major surgical equipment and drugs used in the surgeries are presented in Table 1.

\section{Surgical procedures and extracorporeal circulation}

To ensure the survival of the fetal sheeps, we perform the surgery in a warm animal operating room at $28^{\circ} \mathrm{C}$. The skin of the pregnant sheep's lower abdomen was incised, and the uterus was surrounded with gauze pads moistened with warm saline for support. Anesthetic drugs (fentanyl $25-50 \mu \mathrm{g} / \mathrm{kg}$ and vecuronium bromide $0.1-0.2 \mathrm{mg} / \mathrm{kg}$ ) were injected directly through the uterine wall into the muscles of the fetus's hind limbs, selecting a site without placental vessels. After the fetal movement disappeared, a $4-6 \mathrm{~cm}$ incision was made through the uterine wall in the area without placental blood vessels. Then, the amniotic cavity was opened, the fetal chest exposed, and one upper limb was gently exposed. The axillary artery was exposed and punctured for the placement of a tube to allow monitoring of the fetal arterial blood pressure and heart rate. A mid- 
Eighteen pregnant sheeps were anaesthetised and their uterus was surgically opened to expose the fetal sheep.

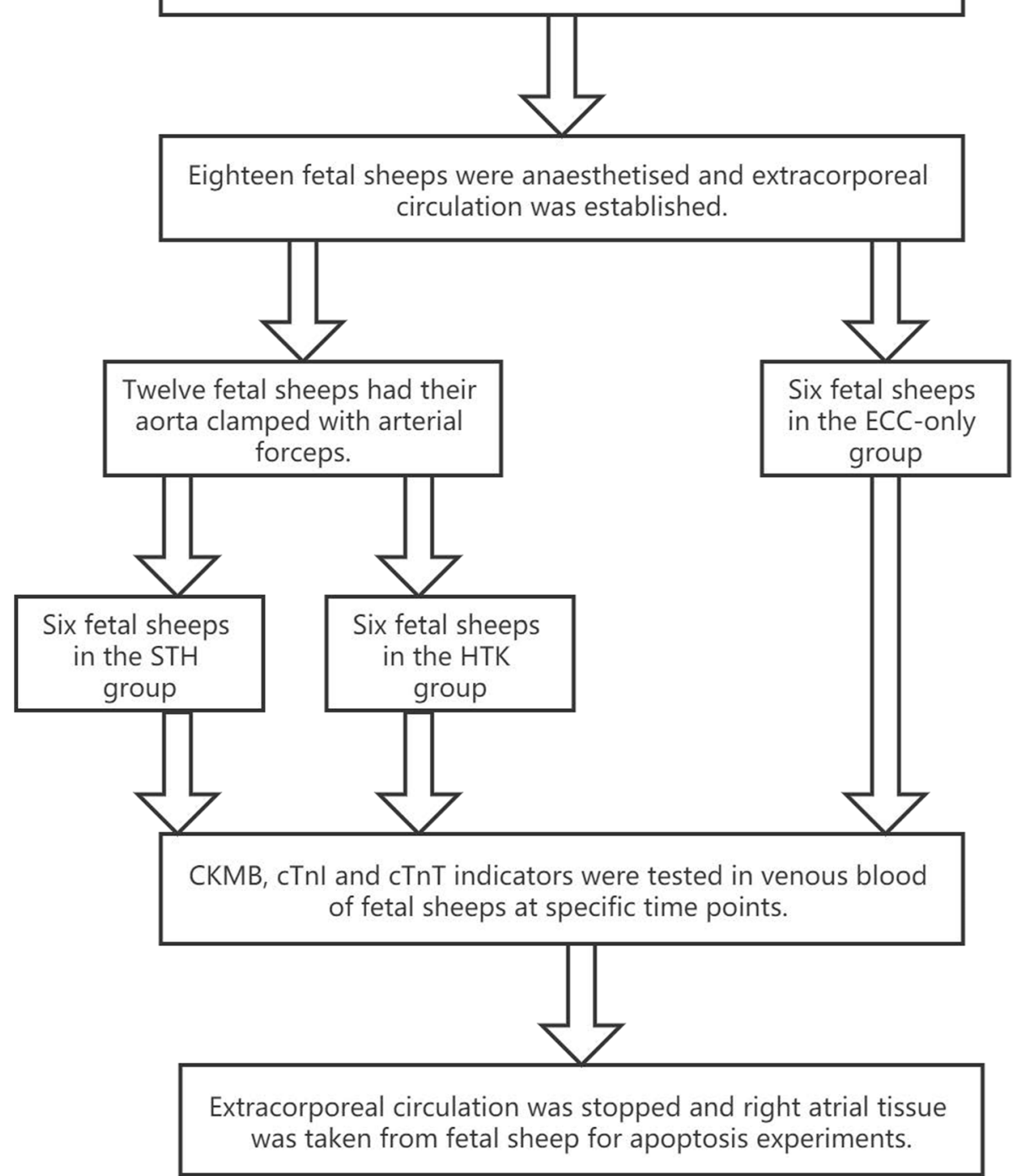

Fig. 1 Study design

Table 1 Major surgical equipment and drugs

\begin{tabular}{|c|c|c|}
\hline Name & Company & Specification \\
\hline Extracorporeal Circulator & STOCKERT,Inc.GER & Shiley \\
\hline Variable temperature water tank & STOCKERT,Inc.GER & 165093 \\
\hline Multi-parameter monitor & GE,Inc.GER & Dragerlnfinity Delt \\
\hline Anesthesia machine & BOCGroup,Inc.USA & EXCEL 210 ANS \\
\hline Fentanyl Citrate Injection & HUMANWELL, CHN & $10 \mathrm{~mL}: 0.5 \mathrm{mg}$ \\
\hline Ketamine hydrochloride injection & HUMANWELL, CHN & $2 \mathrm{mmL}: 0.1 \mathrm{~g}$ \\
\hline Atropine hydrochloride injection & HUMANWELL, CHN & $1 \mathrm{~mL}: 0.5 \mathrm{~g}$ \\
\hline Vecuronium Bromide for Injection & HARBIN MEDISAN PHARMACEUTICAL CO., LTD & $4 \mathrm{mg}$ \\
\hline HTK preservation solution $\left(\right.$ Custodio $\left.^{\circledR}\right)$ & Dr. Franz Koehler Chemie GmnH & $1000 \mathrm{~mL}$ \\
\hline St Thomas' Hospital cardioplegic solution (STH1) & Institute of Cardiovascular Diseases, Guangxi Medical University & $1000 \mathrm{~mL}$ \\
\hline
\end{tabular}


thoracic incision was made on the fetal sheep, and the superficial tissue was incised. The space around the aorta and pulmonary artery was dissected.

In the ECC-only group, we established ECC for the fetal sheep for $60 \mathrm{~min}$, then stopped it and observed the sheep for 120 min. In the STH and HTK groups, the ascending aorta of the fetal sheep was occluded, and the heart was perfused with HTK preservation solution (Table 2) and STH1 (Table 3) to arrest the fetal heart for $30 \mathrm{~min}$. When perfusing the hearts of fetal sheep in the STH and HTK groups, we considered that a lower temperature cardioplegic solution $\left(4^{\circ} \mathrm{C}\right)$ might influence the body temperature of the fetal sheep, so we perfused at a slower rate of $30 \mathrm{~mL} / \mathrm{min}$, with $50-100 \mathrm{~mL}$ per perfusion until the heart arrested. The fetal aorta was then reopened to allow both, body and ECC; after the heart had successfully resumed beating for $30 \mathrm{~min}$, the ECC was stopped, and the sheep were observed for $120 \mathrm{~min}$. The fetal sheep ECC flow rate was above $200 \mathrm{~mL} / \mathrm{kg} /$ min, and the water tank temperature was kept constant at $40{ }^{\circ} \mathrm{C}$. The axillary artery was exposed and a tube was punctured to allow monitoring of fetal arterial blood pressure and heart rate.

The ECC-only group was maintained on the ECC for $60 \mathrm{~min}$ and then arrested for $120 \mathrm{~min}$. After $120 \mathrm{~min}, 5$ $\mathrm{mL}$ of $10 \%$ potassium chloride was injected intravenously into the fetal sheep, and the heartbeat was arrested rapidly. For convenience and efficiency, right atrial tissue was collected from the fetal sheep and stored for subsequent experiments [14]. The fetal sheep were removed and detached from the ECC, and the uterus and abdominal incision of the ewe were sutured. When the ewes awoke from anesthesia, they were returned to the breeding center to continue rearing.

\section{Collection and preservation of specimens}

The venous blood of fetal sheep was collected at various time points and centrifuged at $1500 \mathrm{~g}$ at $4{ }^{\circ} \mathrm{C}$ for $15 \mathrm{~min}$. The supernatant was extracted and transferred to the Eppendorf tubes (approximately $0.5 \mathrm{~mL}$ per tube) and

Table 2 HTK preservation solution (Custodiol ${ }^{\circledR}$ ). Composition. $1000 \mathrm{~mL}$ perfusion solution contains

\begin{tabular}{lll}
\hline $0.8766 \mathrm{~g}$ & sodium chloride & $15.0 \mathrm{mmol}$ \\
$0.6710 \mathrm{~g}$ & potassium chloride & $9.0 \mathrm{mmol}$ \\
$0.8132 \mathrm{~g}$ & magnesium chloride $6 \mathrm{H}_{2} \mathrm{O}$ & $4.0 \mathrm{mmol}$ \\
$3.7733 \mathrm{~g}$ & histidine hydrochloride $2 \mathrm{H}_{2} \mathrm{O}$ & $18.0 \mathrm{mmol}$ \\
$27.9289 \mathrm{~g}$ & histidine & $180.0 \mathrm{mmol}$ \\
$0.4085 \mathrm{~g}$ & tryptophan & $2.0 \mathrm{mmol}$ \\
$5.4651 \mathrm{~g}$ & mannitol & $30.0 \mathrm{mmol}$ \\
$0.0022 \mathrm{~g}$ & calcium chloride.2 $\mathrm{H}_{2} \mathrm{O}$ & $0.015 \mathrm{mmol}$ \\
$0.1842 \mathrm{~g}$ & potassium hydrogen 2-oxopantendioate & $1.0 \mathrm{mmol}$ \\
\hline
\end{tabular}

Table 3 St Thomas' Hospital cardioplegic solution (STH1). Composition. $1000 \mathrm{~mL}$ perfusion solution contains

\begin{tabular}{lll}
\hline $8.4240 \mathrm{~g}$ & \multicolumn{1}{c}{ sodium chloride } & $144.0 \mathrm{mmol}$ \\
$1.4900 \mathrm{~g}$ & potassium chloride & $20.0 \mathrm{mmol}$ \\
$1.5200 \mathrm{~g}$ & magnesium chloride & $16.0 \mathrm{mmol}$ \\
$0.2664 \mathrm{~g}$ & calcium chloride & $2.4 \mathrm{mmol}$ \\
$0.2728 \mathrm{~g}$ & procaine hydrochloride & $1.0 \mathrm{mmol}$ \\
\hline
\end{tabular}

stored at $-80^{\circ} \mathrm{C}$ in a freezer for further testing. The concentrations of troponin $\mathrm{T}(\mathrm{c} T n \mathrm{~T})$, troponin $\mathrm{I}(\mathrm{cTnI})$, and creatine kinase-muscle band (CKMB) in the supernatant were determined by the enzyme-linked immunosorbent assay at five different time points: $\mathrm{T} 1$ (before the start of ECC); T2 (30 min of ECC); T3 (60 min of ECC); T4 (60 min after ECC shutdown) and T5 (120 min after ECC shutdown).

A piece of myocardial tissue of the right atrium of the fetus, of size 1-2 cm, was cut out and placed in a test tube containing $4 \%$ formalin solution, sealed, and kept at room temperature. The tissue was dehydrated and embedded in the paraffin wax for slicing. Cells were uniformly stained with TUNEL to facilitate the observation of apoptosis under a $400 \times$ optical microscope; 10 non-overlapping fields of view were randomly selected, and TUNELstained cells counted. The apoptosis of cardiomyocytes was detected by combining the morphological characteristics and staining of the apoptotic cells. Apoptotic cells were stained brown with the TUNEL stain and exhibited chromatin concentration and fragmentation, DNA marginalization, and the lysis of the nuclear membrane. The apoptotic index was calculated as follows:

$$
\begin{aligned}
& \text { Apoptosis index }(\mathrm{AI})=\text { apoptotic cell number } \\
& \begin{array}{c}
/(\text { number of apoptotic cells }+ \text { number of normal cells }) \\
\times 100 \%
\end{array}
\end{aligned}
$$

\section{Statistical methods}

All data collected in this study were processed using SPSS v.21.0 statistical software (IMB SPSS, Armonk, $\mathrm{NY}$ ), and the results were expressed as mean \pm standard deviation $(\mathrm{x} \pm \mathrm{s})$. Significant differences between two groups were tested using Student's $t$-test, and comparisons between multiple groups were made using one-way analysis of variance $(P<0.05)$. One-way ANOVA set at $P<0.05$ followed by POST HOC LSD $(P<0.05)$ was applied to evaluate differences in myocardial injury marker levels and the number of TUNEL-positive cells between groups at specific time points. $P<0.05$ was considered statistically significant. 
Table 4 Comparison of general information and intraoperative condition of the three groups of fetal sheep $(\bar{x} \pm s)$

\begin{tabular}{llll}
\hline & $\begin{array}{l}\text { ECC-only group } \\
(\boldsymbol{n}=\mathbf{6})\end{array}$ & $\begin{array}{l}\text { STH group } \\
(\boldsymbol{n}=\mathbf{6})\end{array}$ & $\begin{array}{l}\text { HTK group } \\
(\boldsymbol{n}=\mathbf{6})\end{array}$ \\
\hline Age $(\mathrm{d})$ & $123.71 \pm 11.98$ & $122.52 \pm 12.33$ & $130.10 \pm 01.23$ \\
Weight $(\mathrm{kg})$ & $1.21 \pm 0.56$ & $1.24 \pm 0.47$ & $1.33 \pm 0.70$ \\
cardioplegic solutions perfusion $(\mathrm{mL} / \mathrm{kg})$ & - & $47.0 \pm 8.4$ & $58.0 \pm 0.0^{*}$ \\
Time to return to normal heart rate $(\mathrm{s})$ & - & $45.0 \pm 4.3$ & $61.0 \pm 3.5^{*}$ \\
\hline
\end{tabular}

${ }^{*} P<0.05$, comparison with STH group

\section{Results}

\section{Preoperative characteristics}

Twenty-two pregnant sheeps with 22 fetuses were used to develop the ECC direct intracardiac surgery model. Two of the pregnant sheep died of respiratory depression and cardiac arrest during the induction of anesthesia. The remaining 20 ewes were successfully revived after removing the fetuses and were returned to the breeding center. One fetal sheep was intubated into the main pulmonary artery between the outer and middle membranes, which was not detected in time, and it died of cardiac arrest after the start of ECC. Another fetal sheep died due to the failure of cardiac resuscitation, so the experiment was completed with 18 fetal sheeps.

There were no statistically significant differences in the gestational age and body weight between the three groups (Table 4). The STH group had less cardioplegic solutions perfusion than the HTK group $(P<0.05)$, and the STH group required less time to return to a normal heart rate than the HTK group $(P<0.05)$ (Table 4$)$.

\section{Perioperative hemodynamics}

The changes in the heart rate and blood pressure in the three groups of fetal sheep between the T1, T4, and T5 points were not statistically different among the groups. At T2, the STH and HTK groups showed higher ECC flow rate than the ECC-only group $(P<0.05)$. Heart rates were lower in the STH and HTK groups at T3 than at T1 $(P<$ 0.05), and the STH group had lower heart rates than the HTK group $(P<0.05)$. The heart rate at T4 was lower than the basal values at T1 in the STH and HTK groups $(P<0.05)$, and that in the STH group was lower than that in the HTK group $(P<0.05)$. At T3, the mean arterial pressure in the STH group was lower than the basal value at T1 point $(P<0.05)$ and was lower than that in the HTK group $(P<0.05)$. There was no statistically significant

Table 5 Comparison of perioperative hemodynamics in three groups of fetal sheep $(\bar{x} \pm s)$

\begin{tabular}{|c|c|c|c|c|c|}
\hline & T1 & $\mathrm{T} 2$ & T3 & T4 & T5 \\
\hline \multicolumn{6}{|l|}{ Heart rates (bpm) } \\
\hline ECC-only group & $173.1 \pm 20.10$ & $169.1 \pm 17.18$ & $171.7 \pm 22.21$ & $171.5 \pm 18.58$ & $178.1 \pm 10.12$ \\
\hline STH Group & $175.0 \pm 15.12$ & - & $110.3 \pm 22.10^{*}$ & $177.5 \pm 17.14$ & $173.2 \pm 19.56$ \\
\hline HTK Group & $174.6 \pm 21.00$ & - & $151.1 \pm 19.99^{*} \#$ & $174.2 \pm 15.11$ & $177.8 \pm 11.16$ \\
\hline \multicolumn{6}{|c|}{ Average Arterial Pressure (mmHg) } \\
\hline ECC-only group & $57.1 \pm 15.67$ & $57.3 \pm 17.42$ & $56.9 \pm 19.11$ & $57.1 \pm 15.12$ & $56.5 \pm 18.36$ \\
\hline STH Group & $56.9 \pm 13.81$ & $57.5 \pm 13.55$ & $50.0 \pm 16.11^{*}$ & $59.5 \pm 17.22$ & $57.1 \pm 16.39$ \\
\hline HTK Group & $56.9 \pm 16.85$ & $56.6 \pm 17.34$ & $58.0 \pm 19.73 \#$ & $58.2 \pm 16.55$ & $56.8 \pm 15.93$ \\
\hline \multicolumn{6}{|c|}{ ECC flow rate (mL/kg/min) } \\
\hline ECC-only group & - & $101.5 \pm 29.22$ & - & - & - \\
\hline STH Group & - & $114.9 \pm 28.45 \neq$ & - & - & - \\
\hline HTK Group & - & $113.3 \pm 29.76 \neq$ & - & - & - \\
\hline
\end{tabular}

EC Extracorporeal circulation

$\mathrm{T} 1$ : Before start of ECC.

T2: 30 min of ECC.

T3: 60 min of ECC

T4: 60 min after ECC shutdown.

T5: 120 min after ECC shutdown.

${ }^{*} P<0.05$, compared with the pre-ECC; $\# P<0.05$, compared with the STH group; $\neq P<0.05$, compared with the ECC-only group 
Table 6 Changes in the concentration of cTnl in the three groups. $(\bar{x} \pm s)$

\begin{tabular}{llllll}
\hline Groups & T1 & T2 & T3 & T4 & T5 \\
\hline ECC-only group & $59.03 \pm 3.21$ & $58.23 \pm 4.21$ & $60.74 \pm 2.31$ & $65.74 \pm 3.25 \#$ & $73.43 \pm 3.37^{*} \#$ \\
STH Group & $60.21 \pm 3.23$ & $60.38 \pm 5.27$ & $61.70 \pm 4.51$ & $87.52 \pm 4.25^{*} \neq$ & $90.14 \pm 5.96^{*} \neq$ \\
HTK Group & $59.01 \pm 2.19$ & $61.27 \pm 3.43$ & $65.69 \pm 3.24$ & $67.17 \pm 4.56 \#$ & $83.50 \pm 4.63^{*} \neq \#$ \\
\hline
\end{tabular}

ECC Extracorporeal circulation

T1: Before start of ECC.

T2: 30 min of ECC.

T3: $60 \mathrm{~min}$ of ECC.

T4: 60 min after ECC shutdown.

T5: 120 min after ECC shutdown.

${ }^{*} P<0.05$, compared with the pre-ECC; $\# P<0.05$, compared with the STH group; $¥ P<0.05$, compared with the ECC-only group

difference among the groups in the heart rate and mean arterial pressure at $\mathrm{T} 4$ and $\mathrm{T} 5$ (Table 5).

\section{Indicators of myocardial impairment at various time points in different groups of fetal sheep}

There were no significant differences in the serum concentrations of cTnT, cTnI, and CKMB in fetal sheep before the start of ECC between the three groups (Tables 6, 7, 8).

\section{Changes in the concentration of cTnl}

There was no statistically significant difference in cTnI among the three groups at T1, T2, and T3. The cTnI level in the STH group at T4 was significantly higher than that before the start of ECC $(P<0.05)$. The cTnI level in the HTK and ECC-only groups at $\mathrm{T} 5$ was significantly higher than that before the start of ECC $(P<0.05)$. The concentration of cTnI was higher in the HTK group than in the ECC-only group at T5 $(P<0.05)$. The concentration of cTnI was higher in the STH group than in the HTK and ECC-only groups at T4 and T5 $(P<0.05)$ (Table 6 and Fig. 2).

\section{Changes in the concentration of CTnT}

There was no statistically significant difference in $c \operatorname{Tn} T$ among the three groups at $\mathrm{T} 1, \mathrm{~T} 2$, and $\mathrm{T} 3$. The cTnT level in the STH group at T4 was significantly higher than that before the start of ECC $(P<0.05)$. The cTnT level in the HTK and ECC-only groups at T5 was significantly higher than that before the start of ECC $(P<0.05)$. The concentration of cTnT was higher in the STH group than in the ECC-only group at T4 and T5 $(P<0.05)$. The concentration of cTnT was higher in the STH group than in the HTK group at T5 $(P<0.05)$ (Table 7 and Fig. 3 ).

\section{Changes in CKMB concentration}

There was no statistically significant difference in cTnT among the three groups at $\mathrm{T} 1, \mathrm{~T} 2, \mathrm{~T} 3$ and $\mathrm{T} 5$. The CKMB level in the STH and HTK groups at T5 was significantly higher than that before the start of ECC $(P<$ 0.05). The concentration of CKMB was higher in the STH and HTK groups than in the ECC-only group at T5 $(P<0.05)$. The concentration of CKMB was higher in the STH group than in the HTK group at T5 $(P<0.05)$ (Table 8 and Fig. 4).

\section{In situ apoptosis detection in cardiomyocytes}

The apoptotic index was calculated to be $10.2 \pm 4.7$ in the ECC-only group, $34.2 \pm 3.7$ in the STH group, and $20.2 \pm 3.1$ in the HTK group. The number of TUNELpositive cells in the HTK and STH groups was significantly higher than that in the ECC-only group $(P<0.05)$. The number of TUNEL-positive cells in the STH group was significantly higher than that in the HTK group $(P<0.05)$ (Fig. 5).

\section{Discussion}

When the heart arrests, cardiomyocytes still need to be supplied with energy to survive, but their metabolism for generating energy-producing substances is reduced: when they stop contracting, their metabolic rate is only one-tenth that of the beating state [15]. According to

Table 7 Changes in the concentration of cTnT in the three groups $(\bar{x} \pm s)$

\begin{tabular}{llllll}
\hline Groups & T1 & T2 & T3 & T4 & T5 \\
\hline ECC-only group & $101.83 \pm 12.54$ & $100.11 \pm 10.31$ & $104.27 \pm 12.11$ & $105.44 \pm 9.40 \#$ & $119.85 \pm 11.07^{*} \#$ \\
STH Group & $103.57 \pm 16.32$ & $103.49 \pm 10.12$ & $105.96 \pm 17.28$ & $117.31 \pm 7.75^{*} \neq$ & $136.41 \pm 9.02^{*} \neq$ \\
HTK Group & $99.40 \pm 13.53$ & $103.78 \pm 14.56$ & $107.93 \pm 10.85$ & $110.62 \pm 9.54$ & $129.69 \pm 8.90^{*} \#$
\end{tabular}

ECC Extracorporeal circulation

T1: Before start of ECC.

T2: 30 min of ECC.

T3: 60 min of ECC

T4: 60 min after ECC shutdown.

T5: 120 min after ECC shutdown.

* $P<0.05$, compared with the pre-ECC basis; \# $P<0.05$, compared with the STH group; $¥ P<0.05$, compared with the ECC-only group 
Table 8 Changes in the concentration of CKMB in the three groups ( $\bar{x} \pm s$ )

\begin{tabular}{llllll}
\hline Groups & T1 & T2 & T3 & T4 & T5 \\
\hline ECC-only group & $0.51 \pm 0.01$ & $0.51 \pm 0.02$ & $0.55 \pm 0.01$ & $0.56 \pm 0.01$ & $0.59 \pm 0.02$ \\
STH Group & $0.50 \pm 0.04$ & $0.50 \pm 0.08$ & $0.54 \pm 0.08$ & $0.55 \pm 0.02$ & $0.66 \pm 0.03^{*} \neq$ \\
HTK Group & $0.53 \pm 0.01$ & $0.53 \pm 0.04$ & $0.53 \pm 0.07$ & $0.54 \pm 0.03$ & $0.64 \pm 0.06^{*} \neq \#$ \\
\hline
\end{tabular}

ECC Extracorporeal circulation

T1: Before start of ECC.

T2: 30 min of ECC.

T3: $60 \mathrm{~min}$ of ECC.

T4: 60 min after ECC shutdown.

T5: 120 min after ECC shutdown.

${ }^{*} P<0.05$, compared with the pre-ECC basis; \# $P<0.05$, compared with the STH group; $¥ P<0.05$, compared with the ECC-only group

previous studies, St Thomas' Hospital cardioplegic solution (STH1) and HTK preservation solution $\left(\right.$ Custodiol $\left.^{\circ}\right)$ are equally safe in complex paediatric congenital heart surgery [16]. We are neutral on this point of view because fetal and infant heart development are different. There are also relatively few studies on fetal cardioprotection. In this study, cTnI, cTnT and CKMB were chosen as indicators of myocardial injury because these three myocardial biochemical markers have a good parallel relationship with myocardial damage. Myocardial injury marker levels did not differ significantly between groups before the start of ECC, but increased with the onset of ECC, indicating ischaemic and reperfusion injury. The St Thomas' Hospital cardioplegic solution (STH1) does not provide oxygen and rich nutrients to the immature myocardium [17]. In this study, the levels of cTnI, cTnT and CKMB in the HTK group were lower than those in the STH group after ECC, and the number of apoptotic cells was lower.

HTK preservation solution is currently considered to be the best cardioplegic solution. This study showed that
HTK preservation solution $\left(\mathrm{Custodiol}^{\circ}\right)$ was significantly more protective of immature myocardium than $\mathrm{St}$ Thomas' Hospital cardioplegic solution (STH1), and significantly reduced ischaemia and ischaemia-reperfusion injury to immature myocardium due to hypoxic ischaemia. The reasons for this include the fact that the $\mathrm{K}+$ concentration in HTK preservation solution is only 9 $\mathrm{mmol} / \mathrm{L}$, which is significantly lower than that in St Thomas' Hospital cardioplegic solution (STH1), thus avoiding high $\mathrm{K}+$-induced endothelial damage in the coronary arteries and facilitating the maintenance of capillary and extracellular interstitial homeostasis in tissues and organs [18, 19]. In addition, many studies have shown that a single infusion of HTK preservation solution $\left(\mathrm{Custodiol}^{\circ}\right)$ can effectively arrest the heart for 180 min. Because of this feature, HTK preservation solution $\left(\right.$ Custodiol $^{\circ}$ ) protects the myocardial cells better without limiting the duration of the procedure [20]. Endogenous nucleic acid endonucleases cleave DNA at nucleosomes during apoptosis. The TUNEL method actually stains the severed ends of the cut DNA [21]. We observe

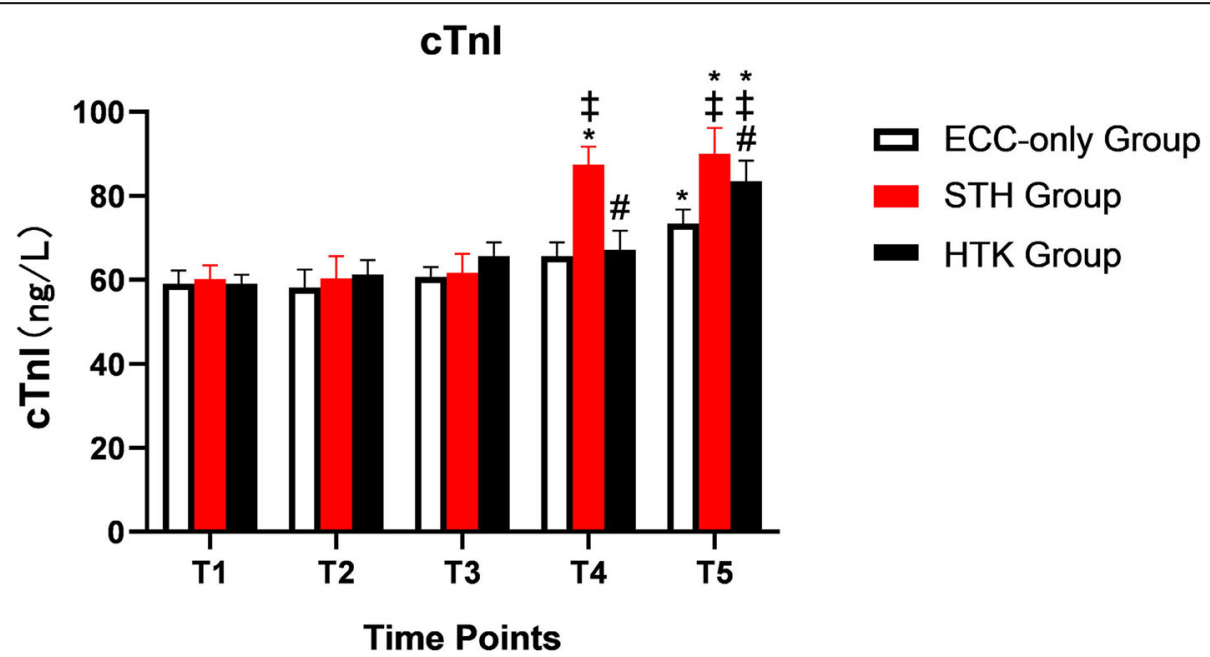

Fig. 2 The concentration of $\mathrm{cTnl}$ in the three different groups. Note: ${ }^{*} P<0.05$, compared with the pre-ECC basis; \# $P<0.05$, compared with the STH group; $\neq P<0.05$, compared with the ECC-only group 


\section{cTnT}

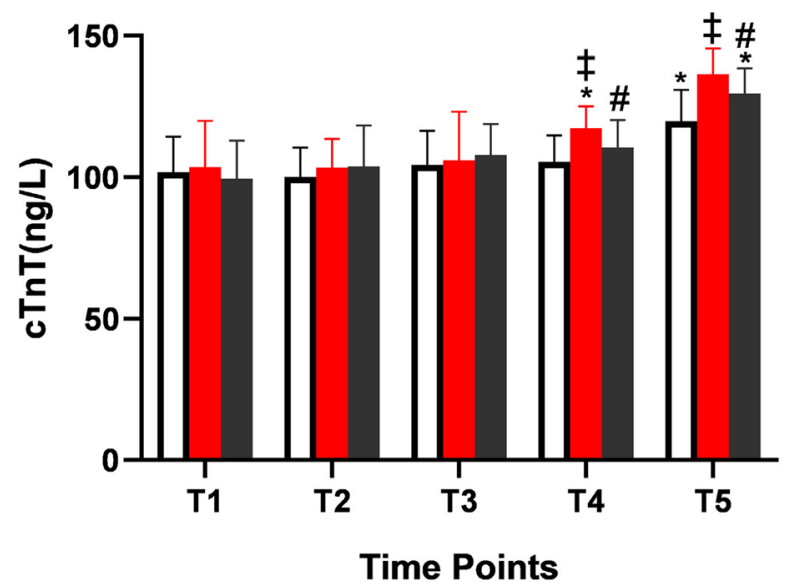

- HTK Group

- STH Group

a ECC-only Group

Time Points

Fig. 3 The concentration of CTnT in three different groups. Note: ${ }^{*} P<0.05$, compared with the pre-ECC basis; \# $P<0.05$, compared with the STH group; $\neq P<0.05$, compared with the ECC-only group

apoptosis by looking at DNA breaks in the nucleus. In this experiment, we found that the number of TUNELpositive cells was higher in the STH group than in the HTK group. This also indicates that HTK preservation solution $\left(\mathrm{Custodiol}^{\circ}\right)$ provides greater protection to cardiomyocytes than St Thomas' Hospital cardioplegic solution (STH1). However, the number of TUNEL-positive cells in HTK group was still higher than in ECC-only group, indicating that the protection of cardiomyocytes by HTK preservation solution $\left(\right.$ Custodiol $\left.^{\circ}\right)$ was also limited.

Our study has some limitations. For example, it is difficult to obtain laboratory animals that are suitable for the conditions, resulting in a small sample size. In immature myocardium, damage due to the ECC often peaks at $6-8 \mathrm{~h}$ postoperatively, and the degree of apoptosis at 120 min postoperatively is not necessarily representative of apoptosis at $6-8 \mathrm{~h}$ postoperatively. Falsepositive results can also occur in TUNEL reactions. We were unable to find a suitable ultrasound instrument to measure the relevant data on cardiac function in real time. The use of data such as heart rate and mean arterial pressure alone does not accurately reflect cardiac function. Moreover, there are genetic differences between human and sheep immature cardiomyocytes. Therefore, more experimental evidence is needed to fully evaluate the cardioplegic solutions effects on the fetal myocardium.

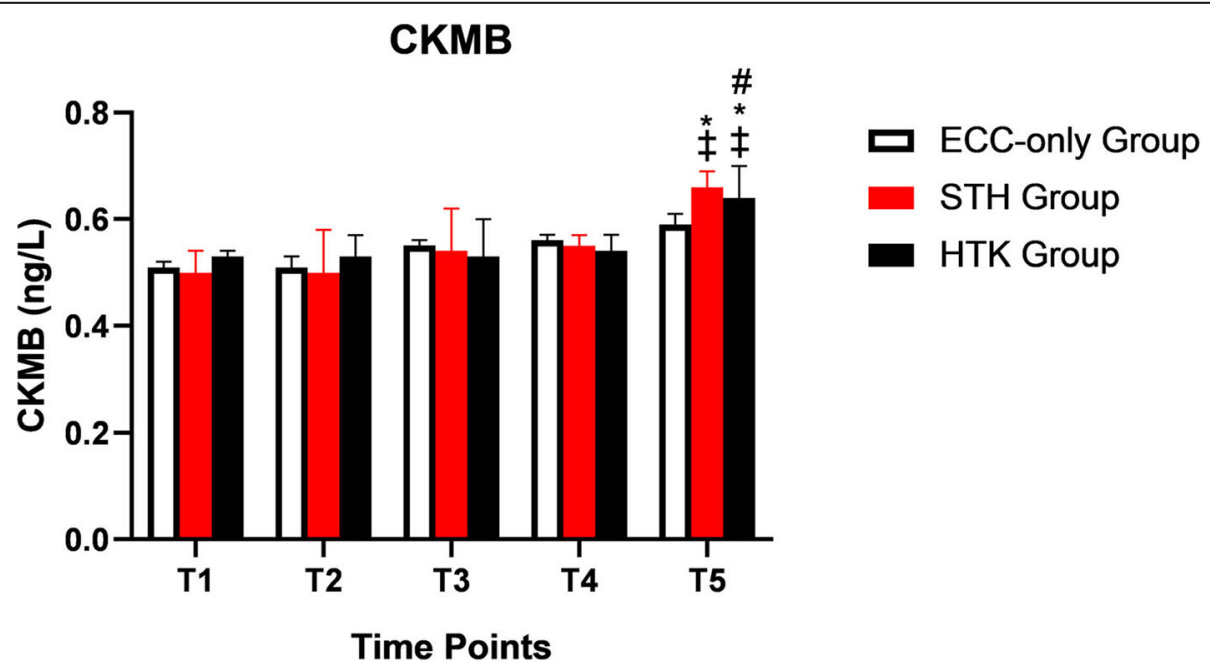

Fig. 4 The concentration of CKMB in three different group. ${ }^{*} P<0.05$, compared with the pre-ECC basis; $\# P<0.05$, compared with the STH group; $\neq P<0.05$, compared with the ECC-only group 


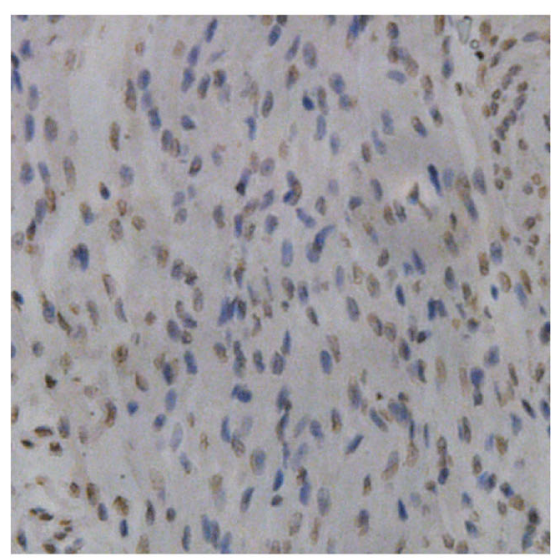

A

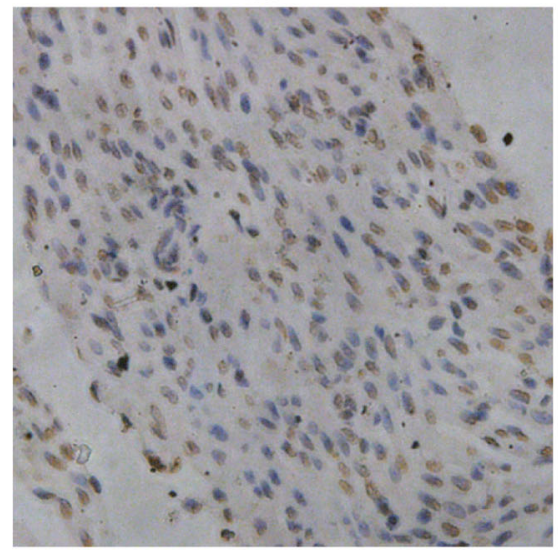

C

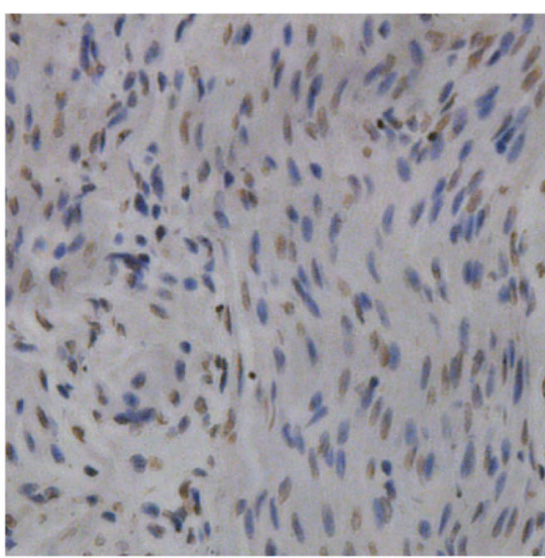

B

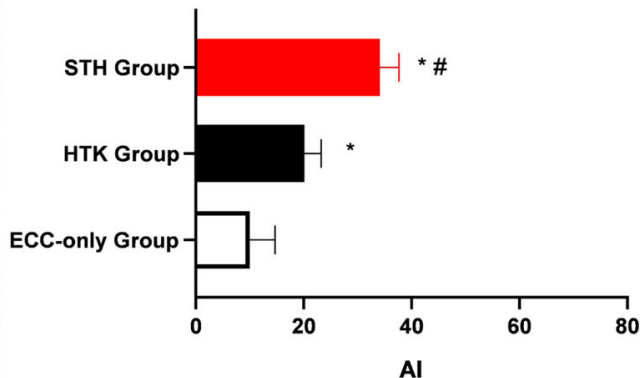

D

Fig. 5 TUNEL assay to detect cell apoptosis (400x). Note: a Apoptosis of cardiomyocytes after ECC in the ECC-only group. b Apoptosis of cardiomyocytes after ECC in the HTK group. $\mathbf{c}$ Apoptosis of cardiomyocytes after ECC in the STH group. $\mathbf{d}$ Comparison of the apoptotic index of the three groups, ${ }^{*} P<0.05$ compared with the ECC-only group; \#P< 0.05 compared with the HTK group

\section{Conclusion}

Our study shows that in an extracorporeal circulation model in fetal sheep, HTK preservation solution (Custodiol $^{\circ}$ ) has a significant advantage over St Thomas' Hospital cardioplegic solution (STH1) in reducing the release of markers of cardiomyocyte injury and a lower number of apoptotic cells. Therefore, HTK preservation solution $\left(\mathrm{Custodiol}^{\circ}\right)$ offered greater protection to cardiomyocytes than St Thomas' Hospital cardioplegic solution (STH1). We found that fetal sheeps using only ECC had an advantage in all indicators. The number of TUNEL-positive cells in the HTK group was higher than that in the ECC-only group, indicating that the protective effect was still limited. It provides a theoretical basis for future fetal heart surgery with ECC only.

\section{Abbreviations}

CKMB: Creatine kinase-muscle band; ECC: Extracorporeal circulation;

cTnl: Troponin I; cTnT: Troponin T; HTK: HTK preservation solution

(Custodiol $\left.{ }^{\oplus}\right)$; STH: St Thomas' Hospital cardioplegic solution (STH1)

\section{Acknowledgments}

Not applicable

\section{Authors' contributions}

All surgical operations performed by YB Yan on the experimental animals were done under the guidance of BF Lei. S Shi and QB Wu were responsible for collecting samples and testing. With the assistance of JS Cai, YB Yan compiled all the data and wrote this article. All author(s) read and approved the final manuscript.

\section{Funding}

Research project funding for young and middle-aged teachers of Guangxi Medical University: 02601216011 C.

\section{Availability of data and materials}

All data generated or analysed during this study are included in this published article [and its supplementary information files].

\section{Declarations}

\section{Ethics approval and consent participate}

All animals were kept in a pathogen-free environment and fed ad lib. The procedures for care and use of animals were approved by the Ethics Committee of the The First Affiliated Hospital of Guangxi Medical University and all applicable institutional and governmental regulations concerning the ethical use of animals were followed. 
Our manuscript does not contain data from any individual person, so "consent participate" is "Not applicable".

\section{Consent for publication}

Our manuscript does not contain data from any individual person, so "consent for publication" is "Not applicable".

\section{Competing interests}

The authors declare that they have no competing interests.

\section{Author details}

${ }^{1}$ Department of Cardiac Surgery, The First Affiliated Hospital of Guangxi Medical University, Nanning, Guangxi Zhuang Autonomous Region, People's Republic of China. ${ }^{2}$ Department of Thoracic Surgery, The First Affiliated Hospital of Guangxi Medical University, Nanning, Guangxi Zhuang Autonomous Region, People's Republic of China.

Received: 17 December 2020 Accepted: 6 April 2021

Published online: 17 April 2021

\section{References}

1. Roger VL, Go AS, Lloyd-Jones DM, Adams RJ, Berry JD, Brown TM, et al. Heart disease and stroke statistics--2011 update: a report from the American Heart Association. Circulation. 2011;123(4):e18-e209. https://doi.org/10.1161/ CIR.0b013e3182009701 Epub 2010 Dec 15. Erratum in: Circulation. 2011 Feb 15:123(6): e240. Erratum in: Circulation. 2011 Oct 18:124(16):e426. PMID: 21160056; PMCID: PMC4418670.

2. Becker S, Hofbeck M, Kendziorra H, Wallwiener D, Mielke G. Double-chamber right ventricle associated with severe fetal cardiac failure. Ultrasound Obstet Gynecol. 2004;23(4):411-3. https://doi.org/10.1002/uog.1027.

3. Huhta JC. Guidelines for the evaluation of heart failure in the fetus with or without hydrops. Pediatr Cardiol. 2004;25(3):274-86. https://doi.org/10.1007/ s00246-003-0591-3.

4. Sklansky M. New dimensions and directions in fetal cardiology. Curr Opin Pediatr. 2003:15(5):463-71. https://doi.org/10.1097/00008480-20031000000003.

5. Sun R, Liu M, Lu L, Zheng Y, Zhang P. Congenital heart disease: causes, diagnosis, symptoms, and treatments. Cell Biochem Biophys. 2015;72(3):85760. 25638345. https://doi.org/10.1007/s12013-015-0551-6.

6. Dolkavt LA, Reimers FT. Transvaginal fetal echocardiography in early pregnancy: normative data. Am J Obstet Gynecol. 1991;165(3):688-91. https://doi.org/10.1016/0002-9378(91)90310-N.

7. Arzt W, Tulzer G. Fetal surgery for cardiac lesions. Prenat Diagn. 2011;31(7): 695-8. https://doi.org/10.1002/pd.2810 Epub 2011 Jun 14. PMID: 21671460

8. Medikonda R, Ong CS, Wadia R, Goswami D, Schwartz J, Wolff L, et al. Trends and updates on cardiopulmonary bypass setup in pediatric cardiac surgery. J Cardiothorac Vasc Anesth. 2019;33(10):2804-13. https://doi.org/1 0.1053/j.jvca.2019.01.025 Epub 2019 Jan 9. PMID: 30738750.

9. Reddy VM, Liddicoat JR, Klein JR, et al. Long-term outcome after fetal cardiac bypass:fetal survival to full term and organ abnormalities [J]. J Thorac Cardiovasc Surg. 1996;111(3):536-44. https://doi.org/10.1016/S00225223(96)70305-7.

10. Duffy JY, Petrucci O, Baker RS, Lam CT, Reed CA, Everman DJ, et al. Myocardial function after fetal cardiac bypass in an ovine model. J Thorac Cardiovasc Surg. 2011;141(4):961-8, 968.e1. https://doi.org/10.1016/j.jtcvs.201 0.08.031 Epub 2010 Sep 29. PMID: 20884028; PMCID: PMC3032026.

11. Reddy VM, Liddicoat JR, Klein JR, McElhinney DB, Wampler RK, Hanley FL. Fetal cardiac bypass using an inline axial flow pump to minimize extracorporeal surface and avoid priming volume. Ann Thorac Surg. 1996; 62(2):393-400. https://doi.org/10.1016/0003-4975(96)00243-3.

12. Oliveira MS, Floriano EM, Mazin SC, et al. Ischemic myocardial injuries after cardiac malformation repair in infants may be associated with oxidative stress mechanisms. [J]. Cardiovasc Pathol. 2011;20(1):e43.

13. Yamamoto F. Metabolic characteristics of immature myocardium. [J]. Gen Thorac Cardiovasc Surg. 2010;58(4):171-3. https://doi.org/10.1007/s11748009-0541-y.

14. Chang JP, Chen MC, Lin WY, Liu WH, Chen CJ, Chen YL, et al. DNA repair in TUNEL-positive atrial cardiomyocytes of mitral and tricuspid valve diseases: potential mechanism for preserving cardiomyocytes. Int J Cardiol. 2011; 146(1):44-50. https://doi.org/10.1016/j.jijcard.2009.06.012 Epub 2009 Jun 27. PMID: 19560219
15. Landymore R, Murphy JT, Hall R, et al. Randomized trial comparing intermittent antegrade warm blood cardioplegia with multidose cold blood cardioplegia for coronary artery bypass [J]. Eur J Cardiothorac Surg. 1996; 10(3):179-84. https://doi.org/10.1016/S1010-7940(96)80294-6.

16. Wang ZH, An Y, Du MC, Qin TJ, Liu YB, Xu HZ, et al. Clinical assessment of histidine-tryptophan-ketoglutarate solution and modified St. Thomas' solution in pediatric cardiac surgery of tetralogy of fallot. Artif Organs. 2017; 41(5):470-5. https://doi.org/10.1111/aor.12771 Epub 2016 Nov 22. PMID: 27878830

17. Gottlieb RA, Gruol DL, Zhu JY, Engler RL. Preconditioning rabbit cardiomyocytes: role of $\mathrm{pH}$, vacuolar proton ATPase, and apoptosis. J Clin Invest. 1996;97(10):2391-8. https://doi.org/10.1172/JCl118683 PMID: 8636421; PMCID: PMC507321.

18. Mohara J, Tsutsumi H, Takeyoshi I, et al. The opti-mal pressure forinitial flush with UW solution in heart procure-ment [J]. J Heart Lung Transplant. 2002: 21(3):383-90. https://doi.org/10.1016/S1053-2498(01)00388-6.

19. Zaman MJ, Vrotsou K, Chu GS, et al. A high incidental rise in cardiac troponin I carries a higher ortality risk in older patients than in those with a diagnosed acute coronary syndrome [J]. Age Ageing. 2011;40(1):122-5. https://doi.org/10.1093/ageing/afq145.

20. Prathanee S, Kuptanond C, Intanoo W, Wongbhudha C, Karunasumaeta C. Custodial-HTK solution for myocardial protection in CABG patients. J Med Assoc Thail. 2015;98(Suppl 7):S164-7 PMID: 26742385.

21. Kyrylkova K, Kyryachenko S, Leid M, Kioussi C. Detection of apoptosis by TUNEL assay. Methods Mol Biol. 2012;887:41-7. https://doi.org/10.1007/ 978-1-61779-860-3 5 PMID: 22566045

\section{Publisher's Note}

Springer Nature remains neutral with regard to jurisdictional claims in published maps and institutional affiliations.

Ready to submit your research? Choose BMC and benefit from:

- fast, convenient online submission

- thorough peer review by experienced researchers in your field

- rapid publication on acceptance

- support for research data, including large and complex data types

- gold Open Access which fosters wider collaboration and increased citations

- maximum visibility for your research: over $100 \mathrm{M}$ website views per year

At $\mathrm{BMC}$, research is always in progress.

Learn more biomedcentral.com/submissions 